\title{
Jogos em situações de ensino-aprendizagem: uma discussão a partir da visão de alguns professores e alunos
}

\author{
Andrea L. Reis \\ PUC - Rio \\ Luiza Novaes \\ PUC - Rio
}

\begin{abstract}
Resumo
Este artigo apresenta os principais resultados de uma pesquisa qualitativa realizada com alunos do Ensino Médio e professores, acerca do uso de jogos em situações de ensino-aprendizagem e do papel do Design nesse processo. O objetivo foi identificar pontos relevantes nos relatos dos alunos e dos professores, para estabelecer um diálogo entre eles e os pensamentos de autores como Morin, Lévy, Brougère e Gee.

Palavras-chave: jogos, educação, design
\end{abstract}

\begin{abstract}
The article presents the main results of a qualitative survey conducted with high school students and teachers concerning the use of games in teaching-learning situations, and the role of design in this process. The goal was to identify relevant issues in the answers of students and teachers, in order to create a dialogue between them and the thoughts of authors like Morin, Lévy, Brougère and Gee.

Keywords: games, education, design
\end{abstract}

\section{INTRODUÇÃO}

Em uma cultura na qual os comportamentos são cada vez mais influenciados pelos ambientes digitais, os jogos aparecem como importante recurso dos processos de ensinoaprendizagem, por trabalharem aspectos como pensamento reflexivo e trabalho colaborativo. Para autores como Huizinga (1938) e Brougère (2000), os jogos sempre foram parte integrante de nossa civilização. A expansão da internet facilitou o acesso a jogos digitais e possibilitou a sofisticação dos gráficos e das animações, aumentando a capacidade de imersão do jogador. Como consequência, os jogos se popularizaram e passaram a ser parte do cotidiano de crianças e de jovens que vivem numa sociedade imersa na cultura digital.

Com base no relatado acima, como parte de uma dissertação de mestrado em Design, 
foi realizada uma pesquisa de cunho qualitativo e exploratório que pudesse ouvir professores e alunos sobre como veem o processo de ensino-aprendizagem mediado por jogos e o papel do Design nesse processo. A análise dos resultados tem como proposta ampliar a visão sobre o tema da pesquisa. Nos relatos dos profissionais e dos alunos, sobre suas vivências com jogos dentro e fora da escola, buscou-se pontos relevantes, comuns e divergentes que pudessem ajudar a traçar um olhar sobre a forma como a escola está organizada nos dias atuais e também subsidiar novas pesquisas de Design, tanto no que diz respeito ao design de jogos, quanto à visão que os professores têm do Design nas situações de ensinoaprendizagem.

\section{PERCURSO METODOLÓGICO}

Para entender a percepção dos professores sobre o uso de jogos em situações de ensinoaprendizagem, foram realizadas 12 entrevistas, tendo como base o Método de Explicitação do Discurso Subjacente, MEDS (NICOLACI-DA-COSTA, 2006). Já em relação aos alunos, adotou-se a técnica de observação por meio de uma experimentação coletiva da versão de tabuleiro do jogo Na Pista do Melhor Caminho ${ }^{l}$, da qual participaram 51 alunos do segundo ano do Ensino Médio, seguida de uma dinâmica em grupo, com oito alunos selecionados dentre os que haviam participado do processo. Na dinâmica em grupo procurou-se utilizar alguns parâmetros da técnica de Grupo Focal.

O critério de seleção de professores para serem entrevistados priorizou aqueles que tivessem experiência com jogos e atividades lúdicas, e também com aulas expositivas. $\mathrm{O}$ recrutamento maximizou a homogeneidade do grupo de participantes, a partir de critérios relevantes para o tema da pesquisa (NICOLACI-DA-COSTA; LEITÃO; ROMÃO DIAS, 2004, p.50)

Outros pontos levados em consideração na seleção dos professores foram:

- gostar de utilizar jogos em situações de ensino-aprendizagem e ter alguma experiência com essa prática;

- ter mais de três anos de experiência profissional; e

- utilizar internet com regularidade no trabalho e em casa..

O número final de professores entrevistados foi estabelecido segundo as orientações do

\footnotetext{
${ }^{1}$ jogo que tem o objetivo de colocar à disposição dos professores do Ensino Médio um recurso de apoio à educação de jovens para o trânsito. Tem como cenário a cidade do Rio de Janeiro e propõe uma abordagem transversal dos temas Juventude e Trânsito, associados à Mobilidade e à Cidadania.
} 
MEDS, que utiliza como parâmetro o "ponto de saturação": o momento em que os novos participantes começam a apresentar discursos semelhantes aos dos já entrevistados, sem introdução de informações adicionais relevantes (NICOLACI-DA-COSTA, 2007).

A experimentação coletiva do jogo e a dinâmica em grupo com os alunos, por sua vez, aconteceram em duas visitas a uma unidade escolar do Sesi. Na primeira visita, que durou $1 \mathrm{~h}$, um dos objetivos foi observar os alunos e selecionar alguns deles para a dinâmica. Ao fim do processo, cada aluno escreveu o que havia achado do jogo. Os temas abordados surgiram de forma espontânea. Esse material nos auxiliou na seleção dos participantes para a dinâmica em grupo e na construção do roteiro de temas para a mesma.

A condução da dinâmica em grupo foi baseada na técnica de Grupo Focal. Segundo definição de Neto, Moreira e Sucena (2002), o Grupo Focal é uma técnica na qual o pesquisador reúne, em um mesmo local e durante um certo período, uma determinada quantidade de pessoas que fazem parte do público-alvo de suas investigações. Tem como principal característica trabalhar com a reflexão expressa por meio da "fala" dos participantes e possibilita que eles apresentem suas impressões e concepções sobre um tema específico, a partir do diálogo e do debate com e entre eles. Ainda como sugerem os autores, a dinâmica teve um roteiro composto por temas-chave; foi conduzida por duas pesquisadoras; contou com a participação de oito jovens (quatro meninos e quatro meninas); e teve duração de aproximadamente uma hora.

\section{OS CRITÉRIOS DE ANÁLISE DOS RESULTADOS}

Os depoimentos foram transcritos na íntegra, buscando preservar o caráter de espontaneidade e os sentimentos vivenciados durante a experiência. Após a transcrição, os dados referentes aos professores foram analisados segundo a orientação do MEDS (NICOLACI-DA-COSTA, 2007), que propõe duas etapas de leitura: interparticipantes e intraparticipantes.

$\mathrm{Na}$ primeira etapa, interparticipantes, as falas são agrupadas e comparadas entre si, buscando pontos recorrentes e, a partir da identificação destes, surgem categorias. Algumas das categorias não foram, portanto, determinadas antes das entrevistas e sim conforme a progressão da análise dos dados. Na etapa denominada intraparticipantes, a leitura e a análise do discurso de cada sujeito é realizada. (NICOLACI-DA-COSTA, 2007).

Os dados coletados na dinâmica com os alunos também foram transcritos na íntegra, passando posteriormente por uma leitura atenta, apesar de não ter sido utilizado o método 
MEDS. A análise dos dados levou também em consideração, assim como nos depoimentos dos professores, as questões recorrentes mencionadas nos depoimentos. Por fim realizamos um cruzamento entre os dados dos dois públicos, procurando convergências e/ou divergências.

\section{PRINCIPAIS RESULTADOS DA PESQUISA DE CAMPO}

\section{A perspectiva dos alunos}

\section{Tema 1: Aprendizados com o Jogo Na Pista do Melhor Caminho}

Pontos levantados espontaneamente: conhecer pontos turísticos de outras regiões do Rio de Janeiro; aprender sobre regras de trânsito; trabalhar pensamento estratégico, capacidade de negociação e matemática. O jogo permitiu mais interação com outros alunos, o que tornou, segundo eles, o aprendizado divertido.

Esse jogo é estratégico porque antes de jogar a gente tem que calcular "se eu fizer
isso aqui... ele pode vir por aqui e chegar antes..."

Eu gostei porque mostra os lugares ... Tem muita gente aqui da Zona Oeste que não conhece a zona Sul, zona Norte. (Menina 1)

\section{Tema 2: Atividades nos momentos de Lazer}

Os jogos digitais estão entre os passatempos preferidos, seguidos das redes sociais. Os meninos citaram o futebol (jogo físico), como terceira opção. Mesmo quando não jogam, o computador é usado para outros fins e atividades, como estudar, desenhar e ver vídeos. Ao serem perguntados se jogam também jogos de tabuleiro, mais da metade respondeu que sim, mas que a cada dia parece mais difícil encontrar parceiros para jogar.

Para o jogo de tabuleiro, é difícil encontrar um parceiro hoje em dia, igual a RPG de mesa. Você gasta um dinheiro para comprar os livros, os tabuleiros, os dados e você não consegue jogar, porque não tem ninguém que queira... (Menino1)

Entre as vantagens dos jogos digitais foram mencionadas: as regras intuitivas; mais autonomia para jogar (não é necessário um outro jogador fisicamente presente); mais capacidade de imersão e interatividade.

Você não precisa ficar tentando entender as regras, ele (o jogo) já tá pronto, então fica mais fácil. E também você não precisa de ninguém, você já tem lá a máquina para jogar contra. (Menino 2)

O jogo de computador é mais real. Parece que é você dentro do jogo. Você realmente se sente um personagem. (Menino 1) 
Apesar de não se reunirem fisicamente, os alunos relataram que jogam online com outras pessoas, reproduzindo no universo digital situações de jogos de tabuleiro. O adversário pode ser um amigo como também alguém desconhecido, de outra cidade ou país.

\section{Tema 3: Jogos de entretenimento e aprendizagem}

Ao conversarmos sobre o que aprendem jogando, responderam que os jogos podem ensinar sobre diversos assuntos e ajudam a desenvolver o raciocínio e a montar estratégias.

Há pouco tempo eu tirei uma nota boa em história por causa de um jogo. Ele fala das batalhas das trincheiras, isso caiu na prova e eu sabia tudo por causa do jogo. (Menino 3)

\section{Tema 4: O formato das aulas}

Os alunos mencionaram que a escola deveria possibilitar aprendizagens mais personalizadas, de acordo com o ritmo e interesse de cada um.

Eu, o Menino 4 e o Menino 2 gostamos muito de Física avançada... mas a gente quer falar coisas mais avançadas e não temos espaço, porque a gente aprende uma matéria fixa, pré-determinada. (Menino 3)

\section{Tema 5: Os aspectos mais importantes de um jogo}

A maior parte dos jovens acha que os aspectos principais são os desafios, a narrativa, a existência de um pensamento estratégico e o conhecimento embutido no jogo.

\footnotetext{
Para mim, o que influencia é realmente a dificuldade e a história. Tem muita gente que não gosta do World of Warcraft por causa dos gráficos, mas lá você aprende a construir uma espada, uma casa. Isso precisa de uma estratégia e você aprende História e Economia. (Menino 1)
}

O interesse por jogos pode desenvolver autonomia e habilidades, mesmo que os jogos não sejam pedagógicos:

Eu e um colega estamos criando um jogo de terror. Ele fez um curso em uma escola de informática. Eu não tenho nenhum curso, eu tive que me virar na modelagem das árvores. Eu sozinho consegui, via computador. (Menino 2 )

Os alunos relataram participar de comunidades online, e que aprendem por meio delas conteúdos de que gostam ou que consideram importantes. Conforme Gee (2012), o uso da tecnologia possibilita às pessoas se organizarem, de acordo com as suas afinidades, em comunidades virtuais e fóruns e aprenderem de forma eficiente nesses ambientes. Também como citado por Ito et al. (2013), a Educação deve trazer para a vida acadêmica assuntos de interesse individual dos alunos, e usar a tecnologia como base para melhor explorar os 
assuntos, com o apoio da família.

\title{
A perspectiva dos professores
}

\section{Tema 1: a motivação dos professores para o uso de jogos}

As principais razões apontadas foram: criar uma relação mais próxima com os alunos, estimulá-los, engajá-los e também ajudá-los a entender conceitos mais facilmente, uma vez que jogando aprendem de forma prazerosa.

\begin{abstract}
Eu era um frustrado: no fim do ano eu tinha mais do que a metade da turma reprovada... um dia caiu uma gaivota de papel, abaixei, peguei e comecei a dar uma bronca na turma: " essa gaivota está mal feita"... Uma aluna perguntou: "E o senhor sabe fazer uma melhor?" e eu falei "sei", então eu ensinei a turma a fazer uma gaivota... Depois fizemos uma guerrinha de gaivotas e no final eu mandei que eles as abrissem e que descobrissem nas linhas de dobras, figuras geométricas... E eu descobri que a atenção da turma ficou enorme e eu passei a fazer um origami com eles a cada dia e a trabalhar um pouco de matemática com origami. (Professor 2)
\end{abstract}

\section{Tema 2: jogos como espaço inter/multidisciplinar que permite que se trabalhe além do conteúdo curricular}

Os professores veem os jogos como importantes espaços para avaliações dos alunos e para trabalharem aspectos de comportamento e relacionamento, posturas diante de situações, dificuldades que possam comprometer o desempenho acadêmico .

O jogo, a atividade lúdica, possibilita ao professor ver aquele aluno que tem dificuldade de se expressar oralmente, o aluno que tem dificuldade de articular as ideias, ... isso é possibilitado em uma atividade que não é aquela de um aluno atrás do outro na fileira de cadeiras em uma aula expositiva. (Professora 5)

Foi apontado também que os jogos permitem trabalhar diferentes conteúdos de modo interdisciplinar, e também possibilitam que os alunos exerçam papéis diferentes no grupo:

$\mathrm{Eu}$ ensino teia alimentar, mas eles estão aprendendo também português, matemática... Você está trabalhando a questão do tempo, está trabalhando o português, a escrita, está trabalhando ciências, informática porque você tem que pesquisar uma imagem... (Professor 3, falando do jogo digital sobre cadeia alimentar, que pediu para os alunos programarem)

Os alunos muito bons de memorizar as coisas, de escrever, de organizar, às vezes não são tão bons de captar uma estratégia de jogo para poder ganhar e isso é muito interessante porque mostra claramente durante as aulas as diferentes habilidades. (Professor 2)

\section{Tema 4: A interação entre os alunos durante os jogos}

Foram ressaltados aspectos como aprender a se relacionar com o outro, a opinar, a negociar e a cooperar. Foi comentado também que a condução do professor e a abordagem do jogo são fundamentais para estimular a cooperação: 
O jogo permite uma troca muito grande entre os alunos também. 'Olha, você não entendeu?' Aí ele explica, porque ele quer que o amigo aprenda a jogar. (Professora 10)

Eles vão ter que discutir e chegar a alguma conclusão. Normalmente quem tem medo de perder pode colocar a sua opinião, mas não vai lutar muito por ela. É um exercício, a criança vai ganhando confiança... (Professora 12)

A dinâmica de interação dos alunos vai muito de como isso é guiado pelo docente. No RPG você pode ter desafios que exijam o trabalho em grupo, e se cada um tentar fazer separado, todos morrem. (Professor 4)

\section{Tema 5: Em relação à utilização do jogo}

Para os participantes, é fundamental ter clareza dos objetivos a serem alcançados com o jogo e saber conduzir a turma em um ambiente mais informal. Caso contrário, o jogo é subutilizado, vira somente diversão, ou não flui.

O jogo é muito bacana, mas o professor tem que saber o que ele quer do jogo porque senão, vai ser uma brincadeira que não vai levar a lugar nenhum, vai ser só uma diversão.... quando você consegue fazer um link entre o jogo e o que você gostaria de desenvolver em termos pedagógicos, você tem um casamento muito especial. (Professora 9)

Cheguei em uma escola e vi os blocos lógicos no chão e perguntei "como é que você trabalha com isso?" aí a professora disse "Não, as crianças é que brincam fazendo figurinha"... (Professor 2)

A maioria dos professores mencionou que é muito difícil utilizar algo totalmente pronto e adequá-lo aos seus objetivos pedagógicos. Apesar de não ser explícito no discurso, deixam transparecer que precisam ser coautores do processo. Ou criam tudo, ou adaptam conceitos de outros jogos. Comentam também que, quando o jogo vem pronto, é preciso haver treinamento para utilizá-lo.

A gente pega um jogo que a gente acha interessante para as crianças e tenta colocar o mais próximo da vida delas. (Professora 10)

A questão do kit didático é equivalente... se eu não capacitar e se eu não mostrar como pode ser usado, como pode ser trabalhada a informação... Vai ficar guardadinho lá no canto... ( Professor 4 )

\section{Tema 6: Sobre o uso de tecnologia em sala de aula}

Mais da metade dos entrevistados não se sente confortável para explorar jogos digitais em sala de aula:

A primeira e única vez que eu trabalhei um jogo virtual eu me arrependi amargamente... ficou uma algazarra tão grande dentro de sala, eles não faziam nada que eu mandava, não respondiam... Talvez se eu dividisse a turma em duas, talvez se eu fizesse outras coisas... Confesso que eu fiquei com um pouco de preconceito... (Professora 7)

Apesar de os computadores da escola de uma das entrevistadas estarem conectados em uma 
rede interna, os professores não planejam atividades que envolvam a interação entre os alunos mediadas por essa rede. As razões apontadas foram a falta de tempo e de ideias para atividades.

A gente tem rede, mas explora pouco... podíamos explorar mais, falta de tempo, eu acho. No jogo virtual, é a criança interagindo com um computador, acho que no concreto, quando você tá jogando, é cara a cara com o seu colega e você questiona. Você pode até questionar o computador, mas não tem muito como convencê-lo de uma coisa. É diferente... (Professora 12)

Entre os que se sentem seguros em utilizar atividades lúdicas que possuam recursos digitais, todos mencionam que o uso da tecnologia pode trazer benefícios para a aprendizagem.

\begin{abstract}
Uma criança criou e programou um joguinho de labirinto... e ali você está trabalhando o quê? Onívoros, herbívoros, carnívoros... produção textual. E ela mostra para a coleguinha, porque tem essa parte de socializar, e aí uma criança aprende a fazer um jogo, com autonomia, sem a ajuda do professor. (Professor 3)

Digital para simular é muito bom... Antigamente eu mandava o aluno fazer vários gráficos. E depois eu colocava em cima do primeiro, que eu chamava de base, um papel manteiga para copiar, fazer um desenho... Hoje em dia faço isso digitando um, dois, três e o gráfico se desloca... Por que não é desenhar o gráfico que é o essencial...O essencial é você saber como um gráfico se transforma em outro... Os ambientes digitais permitem isso com muita facilidade, de você simular e extrair o suprassumo da matemática. (Professor 2)
\end{abstract}

Para Lévy (1999, p.165), a simulação é um modo de conhecimento próprio da Cibercultura. Conforme cita o autor, as técnicas de simulação com imagens interativas não substituem o raciocínio humano, mas prolongam e transformam a capacidade de imaginação e pensamento e, na vida acadêmica, permitem a formulação e a exploração rápida de grande quantidade de hipóteses.

\title{
Tema 7: A visão que têm da escola no que diz respeito ao uso de novas formas de ensino- aprendizagem
}

Para os participantes da pesquisa, de modo geral há resistência e falta de incentivo por parte das instituições de ensino em oferecer formas diferentes de ensino-aprendizagem, principalmente jogos e atividades lúdicas:

\footnotetext{
A gente não costuma ter apoio institucional no sentido de estar recebendo propostas de jogos ou qualquer tipo de formação que nos ajude a formular jogos. Todos os materiais alternativos, que a gente trabalha em sala, são formulados por nós. (Professora 7)
}

Eu tive uma discussão com a coordenação ...Falaram assim: "Olha, você tem que largar o jogo e focar mais no conteúdo" E eu falei : "Não, eu acho que eles estão aprendendo". Eu tenho que pensar nos meus alunos... Eles estão aprendendo toda a 
parte de conteúdo e também coisas que vão levar para o resto da vida deles... (Professor 3)

Uma aluna me disse: "Como eu faço? Comecei a usar tangram com a turma, dei a primeira aula, a coordenadora olhou e depois bateu no meu ombro "Gostei do tangram para a integração com a turma, mas amanhã é aula no quadro, tá?" (Professor 2)

Foi comentado também que não adianta equipar a escola com novas tecnologias, se a forma de ensinar continua a ser a tradicional.

\begin{abstract}
Quando tu observas um comportamento de alguns professores, gestores de escola, embora digam que estão abertos a novas tecnologias, a novas relações e aprendizagens... quando chega no seu fazer, ele vai para o tradicional... Às vezes a pessoa acha também que inserir uma nova tecnologia vai mudar mas não adianta a escola ser equipada com as melhores tecnologias, se chega a parte da aprendizagem vem o tradicional. (Professora 8)
\end{abstract}

Esse depoimento reforça o pensamento de Lévy (1999, p.172), segundo o qual o uso crescente das tecnologias digitais e das redes interativas (redes sociais, mecanismos de buscas e outros) acarreta uma profunda mudança na relação da sociedade com o saber e que as novas possibilidades de criação coletiva distribuída, aprendizagem cooperativa e colaboração em rede oferecidas pelo ciberespaço devem propiciar novas formas de trabalho, tanto nas escolas quanto nas empresa.

Em apenas uma das escolas de Ensino Fundamental e Médio, dentro do universo dos professores entrevistados, há incentivo para o uso de jogos:

A gente tem as orientações mas cabe ao professor também trazer, criar, não é algo que a escola coloca, você vai ter que jogar isso, jogar aquilo, isso fica livre, a gente tem liberdade ... Se eu quiser trazer um jogo daqui a 1 semana, eu posso. (Professora 10)

No entanto, mesmo nessa escola, uma instituição particular de linha pedagógica construtivista, é possível perceber um conflito entre utilizar os jogos e passar o conteúdo, como se o mesmo não pudesse ser passado por meio dos jogos.

A escola trabalha com jogos e acredita muito nisso... Acho até que nos nossos planejamentos a gente devia ter mais jogos, o problema é que a gente corre contra o tempo e aí tem uma coisa de conteúdo, de cumprir currículo. (Professora 12)

Apesar do sentimento expresso pelos entrevistados de que há, de modo geral, falta de incentivo para o uso de jogos e de novas formas de ensino-aprendizagem, três entrevistados mencionaram o surgimento de movimentos isolados de promoção de um ensino mais interdisciplinar, no qual os jogos se destacam por serem um recurso que oferece boas possibilidades para se trabalhar dessa forma. $\mathrm{O}$ entrevistado 2, ao mencionar que as escolas 
começam a usar jogos influenciadas por uma tendência do mercado de treinamentos, reforça o pensamento de Prensky (2012).

Há um movimento no sentido de misturar as matérias e aí os jogos começam a ajudar esse tipo de trabalho... Quer dizer, o foco da educação está mudando ... menos decoreba, uma coisa mais pensada e o jogo faz pensar muito e então os vestibulares começaram a exigir esse tipo de questões por quê? Porque empresas já usam jogos nas suas seleções. (Professor 2)

Eu acredito nas iniciativas individuais, cada um vai sentando, vai fazendo seu projeto, sua política...E a coisa vai se expandindo...Eu acho que é por aí que o negócio vai acontecer... Na verdade, o MEC se você olhar as resoluções, a LDB (Lei de Diretrizes e Bases), ela dá autonomia para a escola...O que falta é a formação do professor... (Professora 1)

Conforme abordado acima, os Parâmetros Curriculares Nacionais, por sua natureza aberta, configuram uma proposta flexível e não um modelo curricular homogêneo e impositivo, que se sobreponha à competência político-executiva dos Estados e Municípios, à diversidade sociocultural das diferentes regiões do País ou à autonomia de professores e equipes pedagógicas. (Parâmetros Curriculares Nacionais, Livro 1, p.13).

\section{Tema 8: A visão que têm sobre o Design}

Mais da metade dos participantes entende que o Design pode colaborar apenas com o aspecto estético de jogos e/ou atividades lúdicas.

Tem design de jogos, design de software,... Mas um designer eu vejo muito mais como uma pessoa ligada à arte. ( Professor 3)

Quando o processo de Design está presente nas escolas, ele é normalmente executado por profissionais com outra formação e os professores não sabem exatamente do que se trata. No depoimento abaixo, a pessoa citada é uma pedagoga que fez cursos de informática, robótica e áreas afins:

Ela cria, mostra possibilidades... ouve se a gente tem novas ideias, daí ela acrescenta outras e pede uns dias para ver em qual programa que ela poderia desenvolver aquilo ali.

Em outro momento da conversa a mesma professora comenta:

Eu acho que um designer criaria jogos atrativos, com um colorido que as crianças gostam... Então eu acho que seria interessante ter uma escola, isso aí é uma coisa bem utópica, trabalhando com Design e aí, "Eu estou precisando disso", o designer vai desenvolve, não assim a toda hora, mas sei lá, duas vezes ao ano, porque a gente sabe que não dá tempo. (Professora10)

A professora 10 mostra contradição em sua fala, pois cita acima, como utopia, algo que já 
acontece na escola e é realizado em uma frequência muito maior do que a mencionada por ela.

Por fim, apesar de ter demostrado em seu depoimento não ter clareza sobre o papel do Design, um outro professor cita uma abordagem do que poderia ser um grupo interdisciplinar para produzir materiais e pensar novas formas de ensino-aprendizagem:

É interessante porque se a gente criasse um grupo de pessoas que fosse produzir materiais que pudessem ser usados em várias disciplinas... Você mudaria o foco da escola... O foco também não seria o jogo, mas o jogo promoveria um foco nas relações... "Ah, você é lá daquela turma, eu sou daqui..." Não, nós vamos estabelecer uma relação e ver o que os jogos poderiam facilitar esse foco nas relações... começariam a melhorar as coisas" (Professor 2)

\section{CONSIDERAÇÕES}

Tanto os professores quanto os alunos apontam a diversão, o desafio, a competição e também a colaboração como as principais motivações dos alunos para a utilização de jogos ou atividades lúdicas, dentro e fora da escola. Os alunos relatam, também, que aprendem conteúdos que fazem parte do currículo escolar por meio de jogos digitais de entretenimento nos momentos de lazer. Essa constatação vai ao encontro do raciocínio de Brougère (2008, p.18), no qual a principal motivação do jogador deve ser a busca do prazer e do divertimento. Isto, porém, não significa que outros efeitos não possam ser conseguidos e incorporados, uma vez que a experiência construída e vivida por meio do prazer pode possibilitar o encontro com aprendizagens e com o desenvolvimento de habilidades. Esses relatos podem ser relacionados também aos pensamentos de Gee (2003, 2009) e Prensky (2012), que defendem a diversão como aspecto mais importante dos jogos digitais no processo de aprendizagem.

Um dos pontos levantados por praticamente todos os professores e também pelos alunos é que os jogos têm a capacidade não só de aproximar o aluno do professor, como de promover a interação entre os alunos. Os depoimentos apontam também a existência de uma relação entre o ganho de qualidade nas relações promovido pelos jogos e uma melhora na performance do aluno.

Em contraponto a alguns professores que relatam não se sentirem à vontade em utilizar os jogos digitais na sala de aula, a familiaridade dos alunos com a tecnologia e com o universo dos jogos faz com que todos comentem que utilizam mais os jogos digitais do que os de tabuleiros nos momentos de lazer. Entre os motivos da preferência, relacionam o processo indutivo com que as regras podem ser descobertas e uma maior possibilidade de imersão no jogo, seja devido à existência de realidade virtual, de simulação, da narrativa, de 
interatividade e/ou pelo modo como o jogo conduz o jogador, ou seja, pela mecânica do jogo. A maneira como todos esses aspectos são conjugados é uma tarefa do Design, como mencionam Church (1999) e Salen \& Zimmerman (2012), e o resultado desse processo é determinante no tipo de experiência que o jogador vivencia. Portanto, mesmo sem terem especificado o termo Design, a importância do processo de Design aparece nos relatos. No entanto, alunos e mais da metade dos professores entrevistados não têm consciência do papel do Design no desenvolvimento de jogos. Ao mesmo tempo que apontam benefícios no uso de jogos nas situações de ensino-aprendizagem, falam também que o papel do Design dentro desse processo é, com frequência, limitado ao seu caráter estético. Apesar de alguns deles já desenvolverem projetos numa lógica de Design, não têm essa consciência. O termo Design é algo que conhecem vagamente, por isso alguns deixam transparecer um pouco de insegurança ao falar sobre o assunto. Conforme Niemeyer (1998), esse entendimento restrito do significado do Design, como atividade que gera valor agregado meramente estético, por parte das professoras, tem raízes históricas:

\footnotetext{
Ao longo do tempo, o design tem sido entendido segundo três tipos distintos de prática e conhecimento. Na primeira o design é visto como atividade artística (...). $\mathrm{Na}$ segunda entende-se o design como um invento, um planejamento (...). Finalmente, na terceira aparece o design como coordenação (...). Neste caso a interdisciplinaridade é a tônica. (NIEMEYER, 1998, p. 24)
}

Embora essas visões e correntes distintas gerem tensões internas no mercado profissional e mostrem uma evolução e fortalecimento do papel do Design na contemporaneidade, ainda hoje, como podemos inferir a partir dos resultados da pesquisa, prevalece no contexto educacional a visão de Design como atividade meramente estética. Esse desconhecimento do potencial do Design contribui para que a interação DesignEducação ainda seja pouco explorada. O pensamento dos professores reforça a pouca compreensão existente da atividade, especialmente no Brasil, conforme abordado por Niemeyer (1998) e a necessidade de se continuar a aprofundar uma discussão epistemológica em torno do Design, conforme preconizam Couto (1997), Bomfim $(1994,1997)$ e mais recentemente Tabak (2012).

Apesar de os professores entrevistados terem mencionado vários benefícios no uso de jogos em sala de aula, como o ganho de autonomia, o aprendizado por meio do prazer e do desafio, a melhora na relação professor/aluno e a capacidade de trabalhar diferentes habilidades, metade dos professores ainda enxerga os jogos como atividade complementar. 
Alguns têm dificuldade de usá-los como substitutos das aulas expositivas. Isso fica claro nos trechos de depoimentos nos quais falam que gostariam de usar mais jogos, mas há pouco tempo para criá-los e, principalmente, muito conteúdo a ser dado.

Por outro lado, os alunos, que possuem o pensamento não linear mais desenvolvido por terem crescido imersos na cultura digital, conforme apontado por Prensky (2012, p.83), sugerem espontaneamente que a escola poderia proporcionar aprendizagens mais individualizadas e com diferentes níveis de desafios a partir dos interesses de cada um.

Somente algumas das escolas dispõem da infraestrutura necessária para pensar novas possibilidades de aprendizagem por meio do uso da tecnologia, como citado por Gee (2003, 2009). No entanto, mesmo nessas escolas, alguns professores ainda não dispõem de conhecimentos suficientes que lhes permitam pensar em possibilidades diferentes de interações entre os alunos, mediadas por computadores, e por isso subutilizam a rede interna da escola. Apesar da existência de uma equipe de informática em algumas escolas, estas também não promovem novas possibilidades de interação. Pode-se pensar se o fato de as equipes serem compostas somente por educadoras ou por pessoas de informática acaba por produzir um olhar disciplinar e restringir a busca por novas formas de ensino-aprendizagem, ao invés de expandi-la. Desta forma, a possibilidade de observação e crítica fica aliada a um único campo de saber. Uma equipe multidisciplinar, como sugere o professor 2, poderia produzir um olhar interdisciplinar mais desejável.

Os professores que entendem os jogos como recursos para trabalhar conteúdos diversos e os usam com mais frequência, apesar de terem tido resultados satisfatórios, tendem a enfrentar resistência da coordenação da escola. Essa situação se agrava no Fundamental II e no Ensino Médio, quando as disciplinas começam a ser dadas por diferentes profissionais e o jogo, que muitas vezes permite uma abordagem multidisciplinar dos conteúdos, acaba não tendo esse espaço junto aos professores, porque cada um está preocupado em dar o conteúdo somente de uma disciplina. Essa postura de alguns professores e, principalmente, das escolas reforça ainda mais um modelo de comunicação de base linear em Educação, situação esta extensamente discutida e criticada, por exemplo, por Edgar Morin em seus textos, com destaque para o livro Educação e complexidade: os sete saberes e outros ensaios (2012, p.76). Nele Morin faz uma crítica "à tradição de pensamento bem enraizada em nossa cultura que molda os espíritos desde a escola elementar e nos ensina a conhecer o mundo por meio de ideias claras e independentes." Para ele, esta tradição estimula a redução do complexo ao 
simples, a separação do que está ligado, a unificação do que é múltiplo e a eliminação de tudo o que traz desordens ou contradições para o nosso entendimento. No entanto, ainda segundo Morin, o problema crucial da contemporaneidade é a "necessidade de um pensamento apto a enfrentar o desafio da complexidade do real, isto é, de perceber as ligações, interações e implicações mútuas, os fenômenos multidimensionais, as relações que são, simultaneamente, solidárias e conflituosas", ou seja, a necessidade de um pensamento transdisciplinar.

\section{REFERÊNCIAS BIBLIOGRÁFICAS}

BOMFIM, Gustavo A. Sobre uma possibilidade de uma teoria do Design. In Estudos em Design. Ano II, Volume II. - Rio de Janeiro, novembro de 1994. p.15-22.

Fundamentos de uma Teoria Transdisciplinar do Design: morfologia dos objetos de uso e sistemas de comunicação. In Estudos em Design. Ano V, Volume II. Rio de Janeiro, dezembro de 1997. P.27-41.

BROUGÈRE, G. Brinquedo e cultura /Gilles Brougère: revisão técnica e versão brasileira adaptada por Gisela Wajskop. Coleção Questões da nossa época: V. 43, 4ª ed. São Paulo: Cortez, 2001.

. Lúdico e educação: novas perspectivas In Linhas críticas, Revista da Faculdade de Educação da UNB, Brasília, V.8 n.14,p.5-20 Janeiro/junho 2002, Disponível em http://periodicos.unb.br/index.php/linhascriticas/article/view/6491/5247. Acesso em 28/03/2016.

CHURCH, Doug. Formal Abstract Design Tools, 1999. In Gamasutra. Disponível em http://www.gamasutra.com/view/feature/131764/formal_abstract_design_tools.php. Acesso em 28/03/2016

COUTO, Rita M. S.. Movimento interdisciplinar de designers brasileiros em busca de educação avançada. Tese (Doutorado em Educação) - Pontifícia Universidade Católica do Rio de Janeiro, 1997.

GEE, James Paul. Deep Learning Properties of Good Digital Games: How Far Can They Go? In Serious Games: Mechanisms and Effects. New York: Routledge, pp. 67-82, 2009. Disponível em http://www.jamespaulgee.com/ . Acesso em 28/03/2016

. What Video Games have to teach us about Learning and Literacy. New York: Palgrave Macmillan, 2003.

HUIZINGA, J. Homo Ludens: o jogo como elemento da cultura. Coleção Estudos. Org. J. Guinsburg. 4a. ed., São Paulo: Perspectiva, 2000. 
ITO, M. et al. Connected learning: an agenda for research and design. In Digital Media and Learning Research Hub, Watkins, Irvine, CA, USA, 2013. Disponível em: http://dmlhub.net.sites/default/files/ConnectedLearning_report.pdf . Acesso em 28/3/2016

GLASS LAB, http://www.glasslabgames.org. Acesso em 28/03/2016

LEVY, P. Cibercultura. Rio de Janeiro: Ed.34, 1999.

A Conexão Planetária, o mercado, o ciberespaço, a consciência. Rio de Janeiro: Ed. 34, 2001.

MINISTÉRIO DA EDUCAÇÃO. Parâmetros Curriculares Nacionais do Ensino Médio. Disponível em http://portal.mec.gov.br/seb/arquivos/pdf/blegais.pdf . Acesso em 28/03/2016

MORIN, Edgard. Educação e Complexidade: os sete saberes e outros ensaios. In: Edgard Morin; Maria da Conceição de Almeida, Edgard de Assis Carvalho, (orgs.);tradução de Edgard de Assis Carvalho. 6a ed. São Paulo: Cortez, 2013.

NA PISTA DO MELHOR CAMINHO, jogo educativo virtual. Disponível em: http://www.conexaoaluno.rj.gov.br/jogos.asp. Acesso em 25/03/2015

NETO, O.C.; MOREIRA, M.R.; SUCENA L.F.M. Grupos Focais e Pesquisa Social Qualitativa: o debate orientado como técnica de investigação. In XIII Encontro da Associação Brasileira de Estudos Populacionais, Minas Gerais, 2002. Disponível em http://www.moodle.ufba.br/file.php/12824/Texto_Pesquisa_Qualitativa.pdf. Acesso em $28 / 03 / 16$

NICOLACI-DA-COSTA, AM. O campo da pesquisa qualitativa e o método de explicitação do discurso subjacente (MEDS). In Psicologia: Reflexão e crítica. Porto Alegre 2007, versão on line. Disponível em http://www.scielo.br/scielo.php?pid=S010279722007000100009\&script=sci_arttext. Acesso em 28/03/2016.

NICOLACI-DA-COSTA, A.M.; LEITÃO, C.; ROMÃO DIAS, D. Como conhecer usuários através do Método de Explicitação do Discurso Subjacente (MEDS). Disponível em http://www2.serg.inf.puc-rio.br/docs/MEDS-IHC2004.pdf. Acesso em 09/11/2013

NIEMEYER, Lucy. Design no Brasil: origens e instalação. Rio de Janeiro: 2AB Editora, 1997.

PRENSKY, M. Aprendizagem baseada em jogos digitais. São Paulo: Editora do Senac, 2012.

, From Digital Natives to Digital Wisdom: Hopeful Essays for 21st Century

Education. California: Corwin, 2012.

SALEN, Katie.; ZIMMERMAN, E. Regras do Jogo: fundamentos do designer de jogos: principais conceitos. Volume1, tradução Edson Furman Kiewicz, São Paulo: Blucher, 2012. 168 p. Título original: Rules of Play: game design fundamentals

TABAK, T, (não) Resolução de (não) problemas: contribuições do Design para os 
anseios da Educação em um mundo complexo. Dissertação (Mestrado), Departamento de Design, Pontifícia Universidade Católica do Rio de Janeiro: 2012.

\begin{abstract}
AS AUTORAS
Andrea L. Reis é Mestre em Design pela Pontifícia Universidade Católica do Rio de Janeiro, PUC-Rio e Bacharel em Comunicação Social com habilitação em Publicidade e em Jornalismo, também pela PUC-Rio. Possui curso de extensão em cinema pela New York University. Atua nas áreas de design e de comunicação, com experiência na criação e coordenação de projetos audiovisuais, digitais e impressos, em especial para as áreas educacional e social. Áreas de interesse: design em situações de ensino-aprendizagem, epistemologia do design, jogos e interatividade.

E-mail: andrea.lennhoff@gmail.com
\end{abstract}

Luiza Novaes é Doutora em Design pela Pontifícia Universidade Católica do Rio de Janeiro, PUC-Rio e Mestre em Fotografia e Mídias Afins, MFA pela School of Visual Arts, em New York, USA. Designer e pesquisadora, atua nas áreas de design como mediação, mídia interativa e comunicação visual. É professora nos cursos de Graduação e de Pós-graduação em Design da PUC-Rio, no Brasil.

E-mail: $\underline{\text { lnovaes@puc-rio.br }}$ 